\title{
Rocking and kinematic analysis of two masonry church façades
}

\author{
L. Giresini \\ Department of Architecture, Design and Urbanistic, University of Sassari, Italy
}

P.B. Lourenço

Departamento de Engenharia Civil, Universidade do Minho, Guimaraes, Portugal

\author{
M.L. Puppio \& M. Sassu \\ Department of Energy, Systems, Territory and Constructions Engineering, University of Pisa, Italy
}

\begin{abstract}
The paper deals with the application of two methods of local analysis on masonry structures. Rocking and kinematic analysis are applied to two cases study: a gable of the Ica Cathedral that survived the 2007 Pisco earthquake and a church façade connected to transverse walls, which collapsed in the 2012 Emilia Romagna earthquake. The critical aspects of both analysis are discussed and the differences in the outputs commented. Being the two rigid blocks at height different from zero, an amplification factor of the seismic record was calculated for performing the rocking analysis. The gable is treated as free-standing block whereas the upper part of the church façade is analyzed in the rocking analysis by accounting for the rebound effect caused by the transverse walls, through the stiffness of a bed spring.
\end{abstract}

\section{INTRODUCTION}

The assumption of masonry panels behaving as set of rigid blocks under earthquakes is widely accepted in literature (Brencich, Lagomarsino 1997). The kinematic chain can be treated with limit analysis, by computing the collapse mechanism multiplier, or by means of rocking analysis (Giresini et al. 2015). The former approach provides an upper limit of the real collapse multiplier and does not consider the evolution of motion over time. The latter point is a key aspect for a correct evaluation of the actual response and can be accomplished by means of rocking analysis throughout integration of the motion equations (Housner 1963). Both typologies are adopted in this paper to discuss the response under earthquake of two masonry elements: the gable of the Ica Cathedral in Peru and one wall of a medieval castle in the Emilia Romagna Italian region.

In a rocking analysis a masonry macro-element can be regarded as single degree of freedom rigid block rotating around its corner base. The radius vector $R$ is the semi-diagonal, while the slenderness ratio $\alpha$ is the arctangent of the ratio thickness to height of the block. Those geometric values are needed to solve the motion equations, together with the acceleration time-history experienced by the block.

The kinematic analysis is the unique tool indicated by Italian codes to perform local analysis for masonry structures constituted by macro-elements. This tool is considered only partially useful by the authors to state the safety conditions of a macro- element. Indeed, as already highlighted and extensively discussed by Makris \& Kostantinidis (2003), a rocking block cannot be assimilated to an equivalent oscillator. Moreover, the Italian codes (NTC2008; Circ.617) define the ultimate displacement capacity of the equivalent oscillator $d_{u}^{*}$ as fraction of the for which the acceleration vanishes. This aspect neglects the dynamic sources of the rocking block, able to survive even when the rotation overcomes the slenderness ratio. In this paper the kinematic non-linear analysis is applied by discussing some aspects in relation to the rocking analysis outcomes.

The verifications performed in the kinematic analysis to state whether a wall is safe under a specific seismic actions are (NTC2008):

$$
d_{u}^{*} \geq S_{D e}\left(T_{1}\right) \frac{Z}{H} \frac{\left(\frac{T_{S}}{T_{1}}\right)^{2}}{\sqrt{\left(1-\frac{T_{S}}{T_{1}}\right)^{2}+0.02 \frac{T_{S}}{T_{1}}}}
$$

if the block is at height $\mathrm{Z}$ different from zero and there is only one floor, whereas:

$$
d_{u}^{*} \geq S_{D e}\left(T_{1}\right)
$$

if the block is on the ground. In these expressions, $S_{D e}\left(T_{1}\right)$ is the displacement demand calculated for the period of vibration of the building $T_{1}$ in the considered direction, $H$ is the height of the building and $T_{S}$ is the secant period of the equivalent oscillator. 


\section{ICA CATHEDRAL}

\subsection{Architectural features}

The Ica cathedral was built in 1759 by the Society of Jesus and used as a place of worship up to the 2007 Pisco earthquake. The city of Ica is located in southern Peru and suffered severe damages and loss of life in that earthquake. In particular, the church was heavily damaged during the Pisco ground motion. Its rectangular plan is constituted by a central nave with four bays, a transept and a altar. The lateral walls are made by mud brick masonry over a fired brick base course and stone arches. The barrel vaults, which cover the building, are completed by wooden arches or ribs and quincha (Getty Conservation Institute 2012). The $1075 \mathrm{~m}^{2}$ church is oriented along and east-west axis, with overall dimensions of $22.5 \times 48.5 \mathrm{~m}$. The east main façade (Fig.1, a) is constructed with fired brick masonry and contains allegorical figures. Two towers, with lower part in brick masonry and upper one in wood frames, are built at the sides of the front façade. This sector experienced relevant damages due to the earthquake, such as diagonal cracks between the façade upper cornice and the base of the bell towers. The gable rocked without overturning during the main shock, as demonstrated by a horizontal crack at its base. A few timber restraints were installed to impede possible collapses after the earthquake (Fig.1, b).

\subsection{Ground motion and soil characteristics}

The 2007 Pisco earthquake struck the central coast of Peru on August 15th at 23.40.57 UTC (6.40 $\mathrm{pm}$ local time). Its duration was about three minutes (Errore. L'origine riferimento non è stata trovata.a) and measured a moment magnitude $\left(\mathrm{M}_{\mathrm{W}}\right)$ of 8.0 (USGS, Harvard CMT). It originated from subduction process between the Nazca plate and the South American continental plate (EERI Special Earthquake Report 2007). The epicenter was approximately $65 \mathrm{~km}$ to the northwest, at a depth of $39 \mathrm{~km}$ (USGS). 519 people were killed by the earthquake. In particular, 17 people, who were attending mass, died and 70 were injured in the collapses that interested the cathedral of Ica. The quake caused enormous damage to earthen buildings, the typology most frequent in the affected area.

The considered seismic record, labeled PRC in the following, is only that of the East-West component, being the longitudinal direction of the church oriented in East-West direction.

\subsection{Rocking analysis}

A rocking analysis is carried out to verify the response of the gable under the seismic action of Par- cona district, registered during the earthquake (USGS).

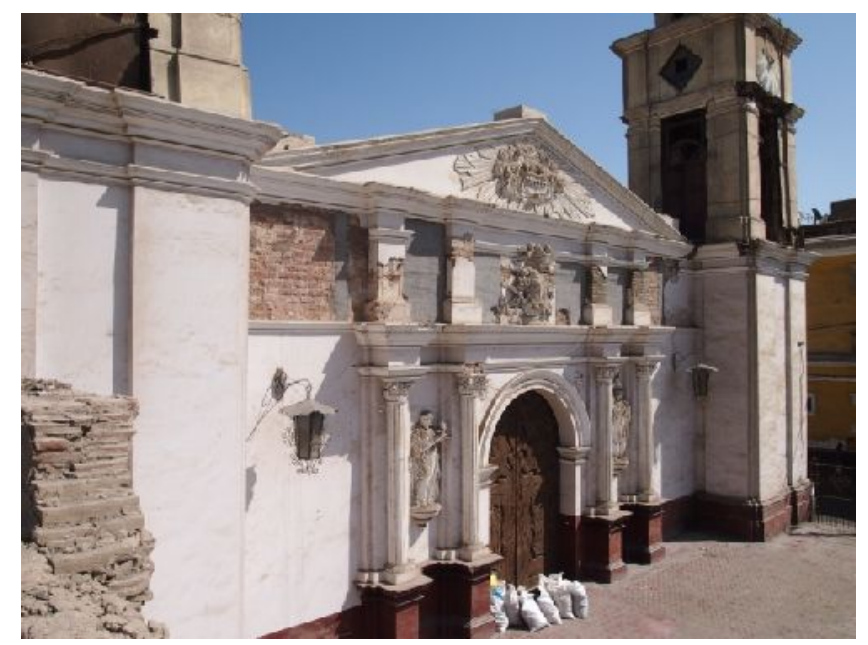

(a)

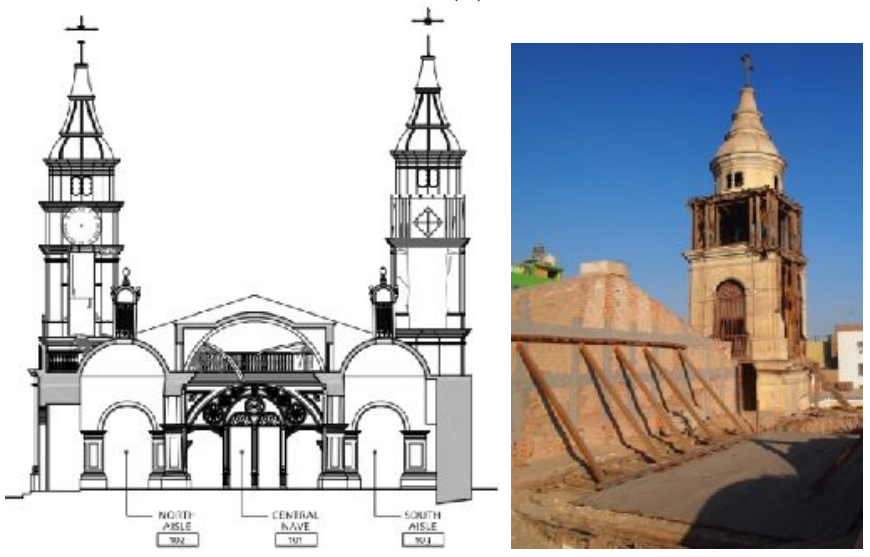

(b)

Figure 1. Front façade of the Cathedral of Ica (a); main façade drawing and view of the gable from the back side (b).

The gable is regarded as single degree of freedom rigid block rotating around its corner base (Figure 3a). $\mathrm{X}$-axis is perpendicular to the rocking block, parallel to the front façade, and passes through $\mathrm{O}$ or $\mathrm{O}^{\prime}$.

The radius vector $R$ is the semi-diagonal, while the slenderness ratio $\alpha$ is the arctangent of the ratio thickness to height of the block. The semi-diagonal has been evaluated by calculating the center of mass of the solid shown in Figure $\mathbf{3 b}$. Those values are obtained by considering the real configuration of the tympanum (Figure $3 b$ ) composed by brick and stone masonry, the latter for the external decorations. Specific weights of respectively 18 and $22 \mathrm{kN} / \mathrm{m}^{3}$ have been used, obtained a weighted (on the volume) average equal to $18.36 \mathrm{kN} / \mathrm{m}^{3}$. The consequent mass density $\left(18.36 / 9.81=18.72 \mathrm{kN} / \mathrm{m}^{3}\right)$ was used to calculate the moment of inertia of the solid in the as built configuration, equal to $J_{X}=406128 \mathrm{~m}^{4}$.

Figure 2 shows the dimensions needed to calculate the polar moment of inertia around the $\mathrm{X}$-axis:

$$
J_{X}=\frac{\rho s \tan \beta}{3}\left[2 h^{2}\left(s^{2}+h^{2}\right)+\bar{h}^{2}\left(s^{2}+\frac{19}{6} h^{2}+\frac{\bar{h}^{2}}{3}+2 h \bar{h}\right)\right]
$$

The geometrical dimensions and mechanical characteristics adopted are displayed in Table 1. Bounc- 
ing and sliding are considered negligible, being the block sufficiently slender (height to thickness ratio larger than 3). The equation of motion written by Housner (1963) is integrated by means of a MATLAB code with a 4th-5th order Runge-Kutta integration technique, implemented in the ODE45 solver (MATLAB INC.). The restitution coefficient is the ratio of the velocity after impact and velocity before each impact, representative of the loss of energy over rocking. The theoretical value of restitution coefficient, equal to $e=1-1.5 \sin ^{2} \alpha$, was considered, by assuming the simplification of rectangular block.

An amplification of earthquake intensity is necessary, being the rocking block at height different from zero. For that, the amplification factor expressed to increase the pseudo-acceleration in the Italian codes is used (NTC2008):

$$
S_{a} \geq \alpha S\left[\frac{3\left(1+\frac{Z}{H}\right)}{1+\left(1-\frac{T_{a}}{T_{1}}\right)^{2}}-0.5\right]
$$

where the term in parenthesis multiplies the acceleration values of the seismic records. $\mathrm{Z} / \mathrm{H}$ is the ratio of the height of the rocking block centroid to the total façade height, while $T_{a} / T_{1}$ is the ratio of the rocking block vibration period to the whole building vibration period in the considered direction. The amplification term to apply for the analysis of the gable is 4.95 , assumed in favour of safety that $\mathrm{T}_{\mathrm{a}} \approx \mathrm{T}_{1}$. Indeed, with adopting the secant period of the rocking block a factor lower than 1 would be obtained, fact that is clearly contradictory. The rotation time-history obtained by the rocking analysis is displayed in Figure 4 and shows that the gable is stable attaining a maximum ratio of normalized rotation angle of 0.29. For comparison purposes, the rocking response of the gable under unscaled seismic record has been reported, registering a maximum normalized rotation about four times lower.

Performing an incremental analysis, the maximum amplification factor to get a safe oscillatory response is equal to 9.9 .

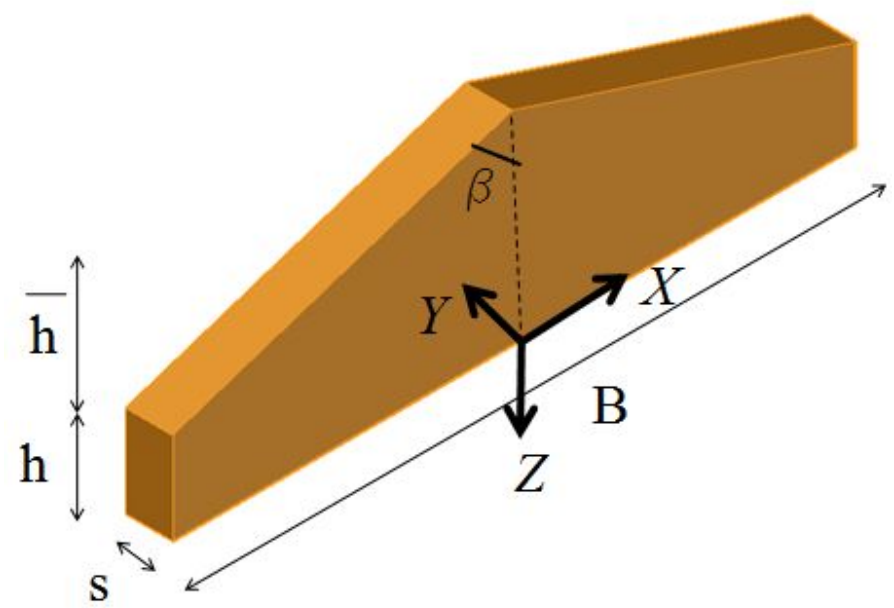

Figure 2. Dimensions of the tympanum.

\subsection{Kinematic analysis}

The kinematic analysis is performed by comparing the displacement demand with the displacement capacity (Equations (1-2)).

Table 1 - Geometric and mechanical features of the tympanum of Ica Cathedral.

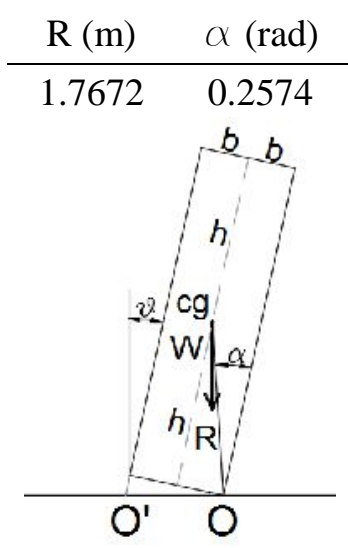

(a)

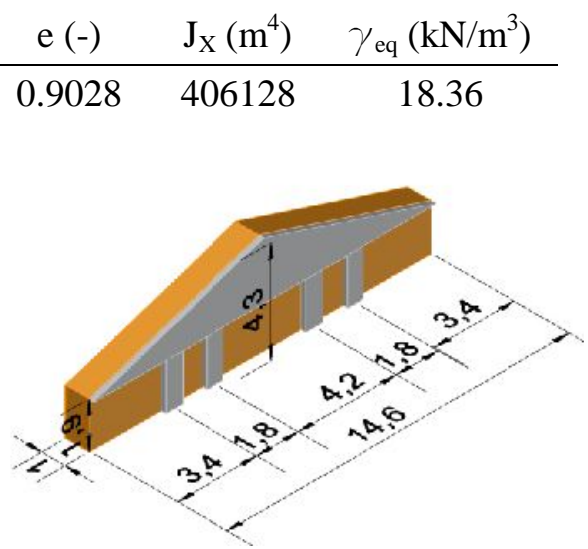

(b)
Figure 3. Rocking single degree of freedom block (a); dimensions of the tympanum in the Ica Cathedral (in meters) (b).

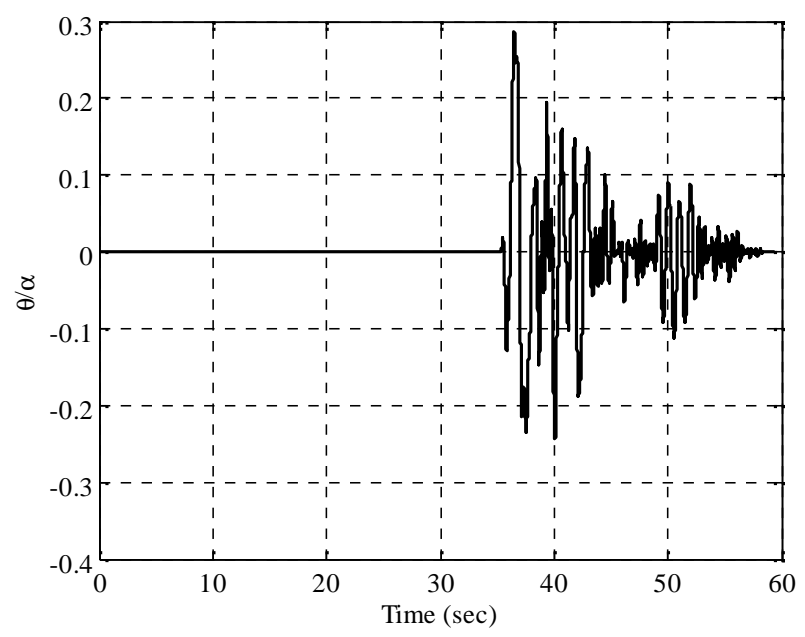

(a)

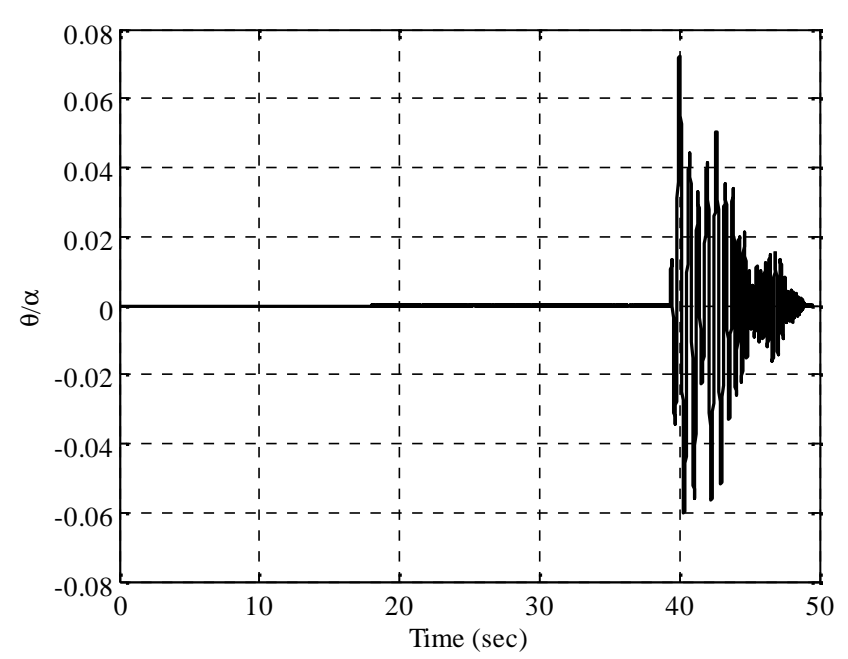

(b) 
Figure 4. Rocking analysis of the gable in the Ica cathedral: PRC seismic record with amplification 4.95 (a); unscaled PRC seismic record (b).

This check must be performed with the two different inequalities shown in the Introduction when the masonry element is at height different from zero.

The demand spectrum has been computed for four values of damping ratio $\xi, 0 \%, 2 \% .4 \%$ and $5 \%$.

First, a finite element model implemented in DIANA provided the natural frequency of vibration of the longitudinal mode, of interest in the analysis of the tympanum.

A value of $2.39 \mathrm{~Hz}$ was obtained, and this mode shape clearly reveals the swinging of tympanum (Figure 6).

The kinematic non-linear analysis suggests that the damage limit state is attained, since the acceleration that triggers the tympanum mechanism is equal to $0.26 \mathrm{~g}$ and the peak ground acceleration of the $\mathrm{PRC}$ record is $0.49 \mathrm{~g}$.

Nevertheless, according to the Italian codes the ultimate limit state is abundantly overcome when the mechanism is considered at height $\mathrm{Z}$ different from zero, highlighting that the conservative character of this analysis.

Moreover, from Table $\mathbf{2}$ it is possible to see that, varying the damping ratio, related to the inelastic capacity of the building, the demand displacement $\mathrm{S}_{\mathrm{D}, \mathrm{e}}\left(\mathrm{T}_{\mathrm{S}}\right)$ widely changes, even though this is always lower than the ultimate limit displacement $d_{u}^{*}=$ $16.40 \mathrm{~cm}$. These aspects stress uncertainties existing on the choice of ultimate capacity displacement and of the demand displacement spectrum, which can be crucial for the analysis outcome.
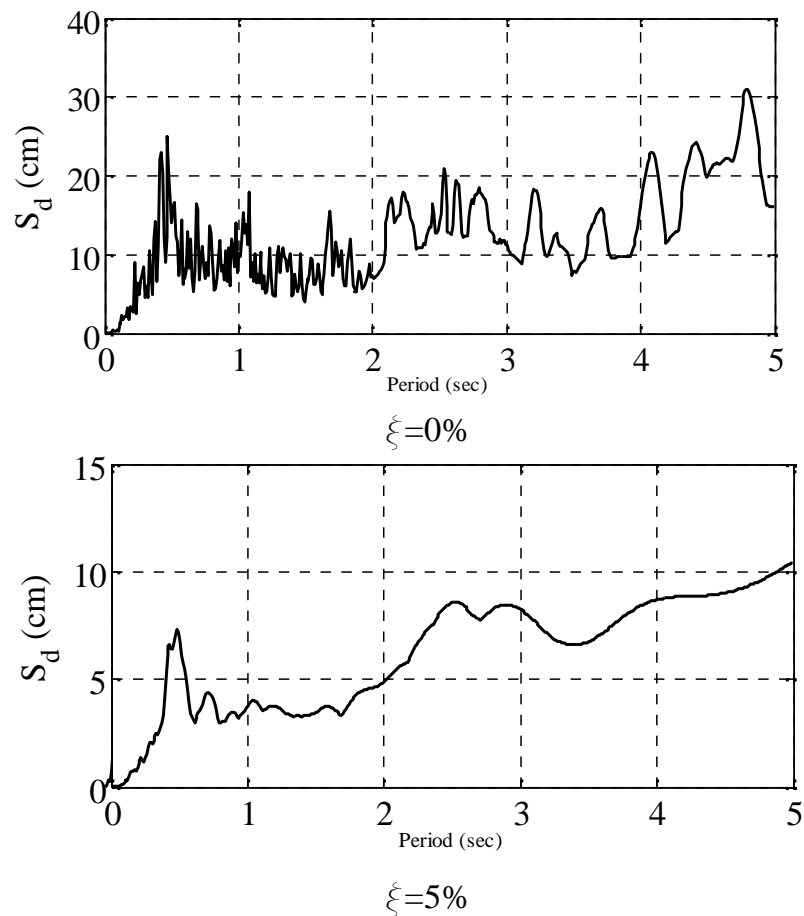

Figure 5. Pseudo-displacement spectra for different damping ratios (PRC seismic record).

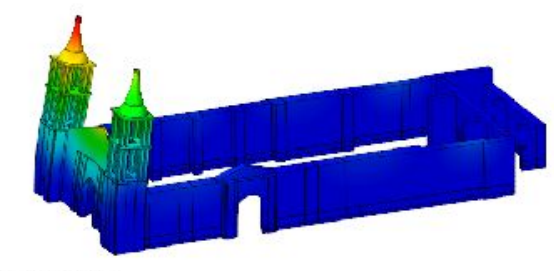

Figure 6. Longitudinal mode shape in the finite element model of the church (DIANA software).

Table 2 - Displacement demand parameters and kinematic analysis outcomes for the gable.

\begin{tabular}{|c|c|c|c|c|}
\hline $\begin{array}{l}\xi \\
\% \\
\%\end{array}$ & $\begin{array}{l}\mathrm{S}_{\mathrm{De}} \\
\left(\mathrm{T}_{1}\right)\end{array}$ & $\begin{array}{l}S_{\mathrm{D}, \mathrm{e}} \\
\left(\mathrm{T}_{\mathrm{S}}\right)\end{array}$ & $\begin{array}{l}\text { On the ground } \\
\text { (ULS) } \\
\text { Equation (2) }\end{array}$ & $\begin{array}{c}\text { At height } \mathrm{Z}=6.12 \mathrm{~m} \\
\text { (ULS) } \\
\text { Equation (1) }\end{array}$ \\
\hline 0 & 22.09 & 10.23 & safe & unsafe \\
\hline 2 & 7.384 & 4.48 & safe & unsafe \\
\hline 4 & 6.88 & 3.87 & safe & unsafe \\
\hline 5 & 5.197 & 3.71 & safe & unsafe \\
\hline
\end{tabular}

\section{SS. GIACOMO AND FILIPPO CHURCH}

\subsection{Architectural features}

The SS. Giacomo and Filippo church is located in the village of S. Giacomo Roncole, in Emilia Romagna Italian region. The church, in the municipality of Mirandola, was built in the 13th century, rebuilt in the 17th and again modified in 1794. The church has one nave with two side chapels and is constructed with brick masonry and clay mortar. Lathing vaults and queen post trusses cover the building. The façade width is $14 \mathrm{~m}$ and the maximum height about $13 \mathrm{~m}$. Its upper part, including the gable, was heavily damaged in the first main shock on May 20th, revealing an incipient overturning mechanism (Figure 7a), and collapsed after the second quake on May, 29th (Figure 7b).

\subsection{Ground motion and soil characteristics}

The 2012 Emilia Romagna earthquake consisted in two main shock occurred on May 20th and 29th. The epicentre of the first was at about $20 \mathrm{~km}$ away from the SS. Giacomo and Filippo church, in the municipality of Finale Emilia (Modena), $\mathrm{M}_{\mathrm{L}}=5.9$ and hypocenter at depth of $6.3 \mathrm{~km}$. This earthquake caused 7 fatalities, 50 injuries and severe damages to the historic heritage buildings and industrial facilities.

The second main shock had the epicentre between Mirandola, Medolla and Felice sul Panaro, $M_{L}=5.8$ 
and hypocenter at depth of $9.6 \mathrm{~km} .20$ fatalities were reported and more than 150 were injured in the event. Liquefaction phenomena occurred during both the main shocks, causing also collapses of new buildings.

The seismic records chosen for the analysis (Luzi et al. 2008, 2008; Pacor et al. 2011, Table 3) are those registered by stations nearly to the church, without any amplification factor related to soil conditions.

Table 3 - Seismic records of the 2012 earthquake (East-West component) with the distance of the station from the church.

\begin{tabular}{ccccc}
$\begin{array}{c}\text { EQ } \\
\text { code }\end{array}$ & Date \& time & $\begin{array}{c}\text { PGA } \\
\left(\mathrm{m} / \mathrm{s}^{2}\right)\end{array}$ & $\begin{array}{c}\text { PGV } \\
(\mathrm{cm} / \mathrm{s})\end{array}$ & $\begin{array}{c}\text { Distance } \\
(\mathrm{km})\end{array}$ \\
\hline MRN & $\begin{array}{c}05.20 .2012 \\
\text { UTC02:03:52 }\end{array}$ & 2.57 & 29.97 & 3 \\
\hline MRN & $\begin{array}{c}05.20 .2012 \\
\text { UTC03:02:50 }\end{array}$ & 1.72 & 6.82 & 3 \\
\hline MRN & $\begin{array}{c}05.29 .2012 \\
\text { UTC07:00:03 }\end{array}$ & 2.19 & 28.51 & 3 \\
\hline MIR01 & $\begin{array}{c}05.29 .2012 \\
\text { UTC07:00:03 }\end{array}$ & 4.11 & 31.32 & 4 \\
\hline MOG0 & $\begin{array}{c}05.29 .2012 \\
\text { UTC07:00:03 }\end{array}$ & 2.36 & 26.62 & 16
\end{tabular}

\subsection{Rocking analysis}

The rocking analysis is performed by integrating the equation of motion of the façade subjected to the earthquakes described in Table 3. To take into account the transverse walls effects, two types of analyses are carried out.

The first considers the portion of transverse walls participating to motion with their own stiffness, estimated with a constant stiffness per unit surface as spring bed connected to the façade (Giresini \& Sassu 2015):

$$
K^{\prime}=2 \times \frac{\mathrm{E}_{\mathrm{x}} t}{L}
$$

being $\mathrm{E}_{\mathrm{x}}$ the masonry elastic modulus in the horizontal direction, $t$ the thickness and depth of the participating transverse walls and $\mathrm{L}$ the length of the perpendicular walls portion involved in the rocking motion. If the motion is one-sided, as it is for the considered masonry façade, the stiffness acts only for clockwise or counterclockwise rotations. The damping effect are here considered separately by assuming the reduction of the velocity after impact by the restitution coefficient, as usually done in the dynamics of rocking blocks (Housner 1963).

As proposed by Sorrentino et al. (2008), the second method consists in changing the velocity after impact $\dot{\theta}_{2}^{\text {imp }}$ according to the expression:

$$
\dot{\theta}_{2}^{i m p}=-r_{f} e \dot{\theta}_{1}^{i m p}
$$

where $\dot{\theta}_{1}^{i m p}$ is the velocity immediately before impact, $e$ the restitution coefficient and $r_{f}$ a damping factor $\leq 1$.

Prior to rocking as free block, the façade displayed in Figure 7a likely accounted for the portion of transverse walls identified by the crack as horizontal boundary conditions.

The analysis is performed by applying both set of earthquakes occurred on the May 20th and 29th. The amplification factor accounting for the fact that the rocking block is at height $\mathrm{Z}$ different from zero is again obtained by Equation (3): as done in the previous case, $\mathrm{T}_{\mathrm{a}} \approx \mathrm{T}_{1}$ is assumed to maximize the amplification factor, obtaining a value of 4.87. The collapse condition is fixed when the maximum rotation attains $\pi / 2$, namely for a normalized rotation $\vartheta / \alpha=17.3$.

Let us consider a bed spring stiffness of 1E10 $\mathrm{N} / \mathrm{m}^{2}$, obtained by assuming a horizontal elastic modulus of $4000 \mathrm{MPa}, \mathrm{L}=0.40 \mathrm{~m}$ (average value) and $\mathrm{t}=0.50 \mathrm{~m}$. The response, displayed in Figure 8a, shows the rebound effect performed by the transverse walls.

The maximum damping factor of the Sorrentino et al. approach (2008) is obtained from a back analysis, knowing that the façade was stable under the earthquake occurred on May, 20th. The maximum $r_{f}$ for which the façade is stable is 0.95 .

The peak of the response is very similar to that resulted from the first method, between 0.40 and 0.50 (Figure 8). Nevertheless, the content frequency is markedly different for the two cases.

For the second set of earthquakes occurred on May 29th, the rocking analysis is carried out with the Sorrentino et al. approach (2008). For maximizing the response, a damping factor $r_{f}$ equal to 1 has been adopted. Figure 9 displays the dynamic response of the upper façade: the rebound effect is such that no collapse occurs for the unscaled earthquakes (a,b,c), while with the assumed amplification factor the block is unstable for all the earthquakes (d).

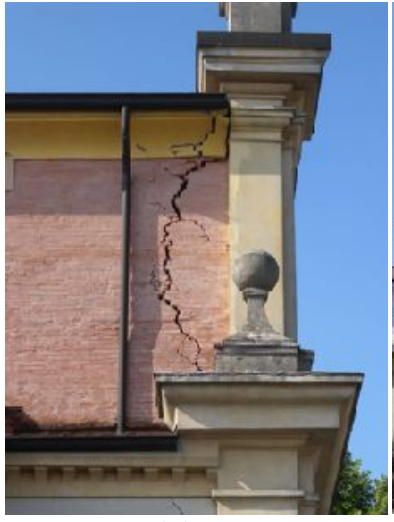

(a)

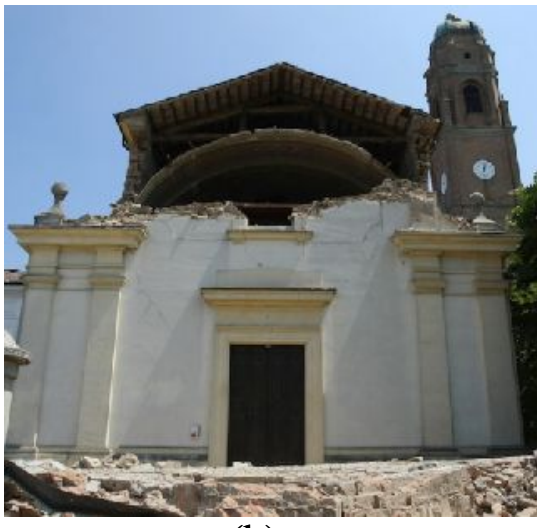

(b) 
Figure 7. Incipient overturning mechanism after the May, 20th earthquake (a) and the overturned façade after the May, 29th earthquake (b).

This highlights the relevance of properly defining the amplification factor for elements not lying on the ground, whose determination is very complex being related to the supporting structure behavior, boundary conditions, record type. Moreover, the minimum amplification factor for which the façade would have been stable (considering e.g. MIR01) For the stable cases, the larger the PGV, the larger the maximum normalized rotation.

\subsection{Kinematic analysis}

The first vibration period is calculated with the simplified formula $\mathrm{T}_{1}=\mathrm{CH}^{3 / 4}=0.41 \mathrm{~s}$, where $\mathrm{C}=0.06$ and $\mathrm{H}$ is the total height of the building (NTC2008).

Considering that $d_{u}^{*}=6.45 \mathrm{~cm}$, the ultimate state (Equation 1) is attained for the earthquake occurred on May 20th, resulting in unsafe conditions for all the damping ratios $\xi$ (Table 4). Also for the earthquake of May 20th, for which the façade survived, the kinematic analysis indicate unsafe conditions. Therefore, again the kinematic analysis is shown to be conservative with respect to the rocking analysis.

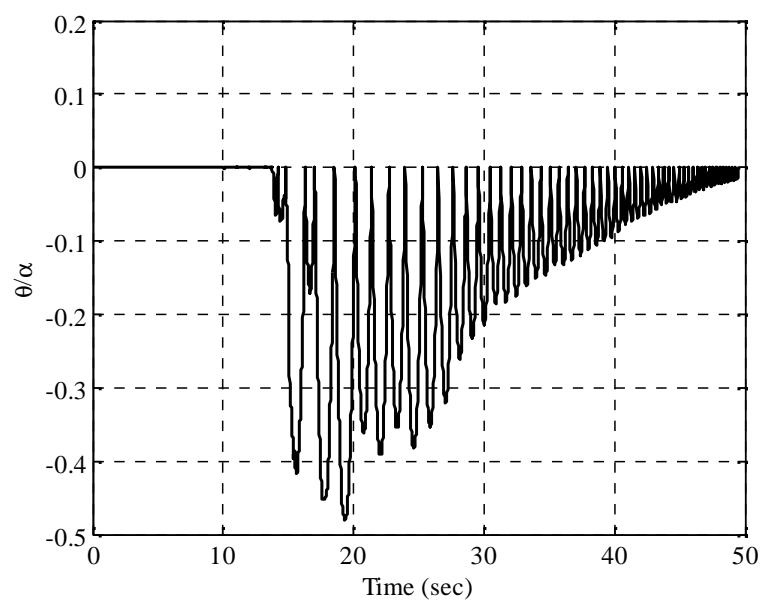

(a)

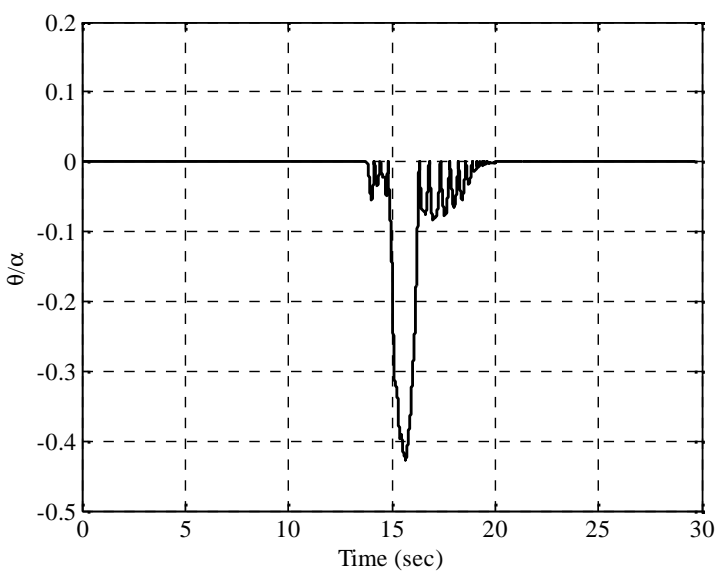

(b)

Figure 8. Rocking analysis of the façade of the SS. Giacomo and Filippo church in Roncole under the May, 20th earth- quake: Mirandola MIR01 seismic record with amplification factor 4.87 and $\mathrm{K}^{\prime}=1 \mathrm{E} 10 \mathrm{~N} / \mathrm{m}^{2}$ (a); Mirandola MIR01 seismic record with amplification factor $4.87, \mathrm{r}_{\mathrm{f}}=0.95$ (b).

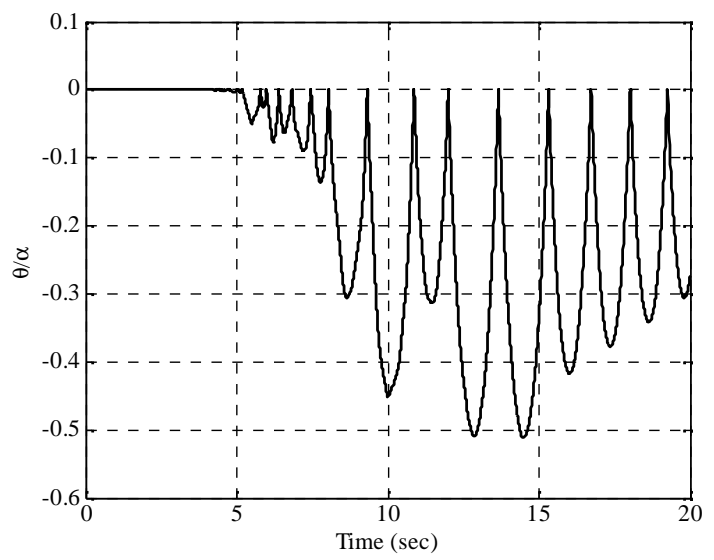

(a)

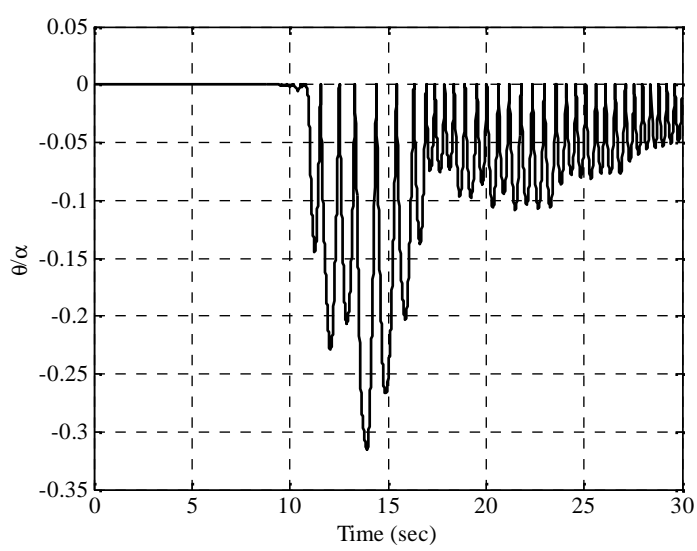

(b)

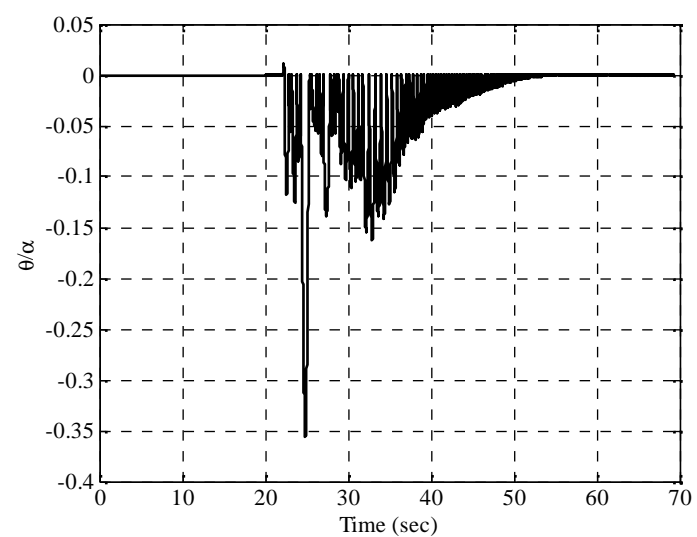

(c)

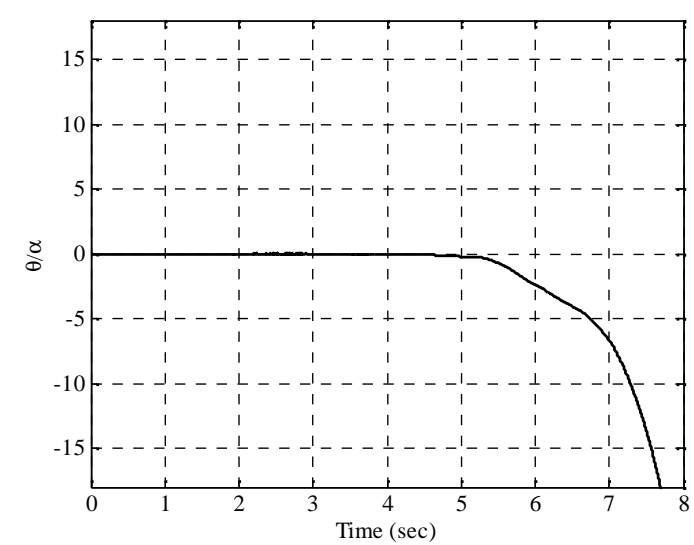

(d)

Figure 9. Rocking analysis of the façade - May, 29th earthquake: unscaled Mirandola MRN seismic record, $\mathrm{r}_{\mathrm{f}}=1$ (a); un- 
scaled Moglia MOG0 seismic record, $\mathrm{r}_{\mathrm{f}}=1$ (b); unscaled Moglia MIR01 seismic record, $\mathrm{r}_{\mathrm{f}}=1$ (b); Mirandola MRN seismic record with amplification factor $4.87, \mathrm{r}_{\mathrm{f}}=1(\mathrm{~d})$.
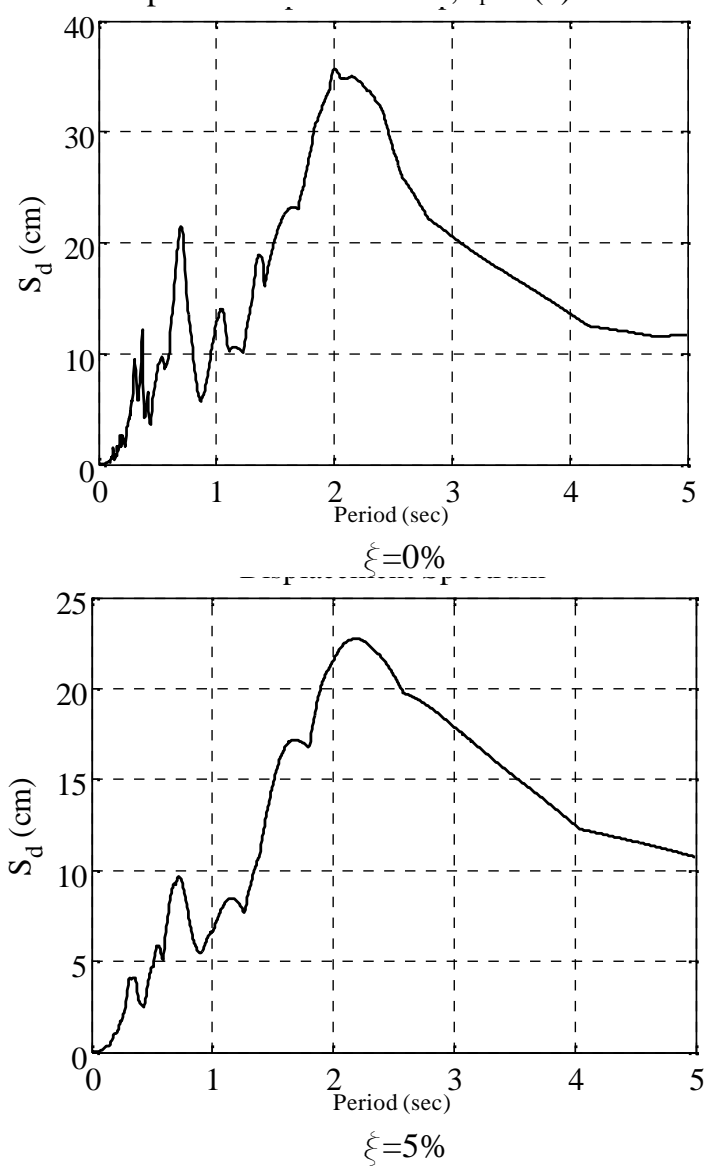

Figure 10. Pseudo-displacement spectra for different damping ratios (MIR01 seismic record).

Table 4 - Displacement demand parameters and kinematic analysis outcomes (MIR01).

\begin{tabular}{|c|c|c|c|c|}
\hline $\begin{array}{l}\xi \\
\%\end{array}$ & $\begin{array}{l}\mathrm{S}_{\mathrm{De}} \\
\left(\mathrm{T}_{1}\right)\end{array}$ & $\begin{array}{l}\mathrm{S}_{\mathrm{D}, \mathrm{e}} \\
\left(\mathrm{T}_{\mathrm{S}}\right)\end{array}$ & $\begin{array}{l}\text { On the ground } \\
\text { (ULS) } \\
\text { Equation (2) }\end{array}$ & $\begin{array}{c}\text { At height } \mathrm{Z}=6.12 \mathrm{~m} \\
\text { (ULS) } \\
\text { Equation (1) }\end{array}$ \\
\hline 0 & 6.60 & 10.56 & safe & unsafe \\
\hline 2 & 2.78 & 9.14 & safe & unsafe \\
\hline 4 & 2.76 & 8.06 & safe & unsafe \\
\hline 5 & 3.10 & 7.97 & safe & unsafe \\
\hline
\end{tabular}

\section{CONCLUSIONS}

This paper applied two different methods of local analysis on masonry structures to two cases of church façades. The results of the kinematic and rocking analysis, intrinsically different methods, were commented for a gable that survived 2007 Pisco earthquake and a façade that collapsed during the 2012 Emilia Romagna swarm. For the considered cases, the kinematic analysis provided conservative results with respect to the rocking analysis. However, kinematic analysis face uncertainties on the choice of ultimate capacity displacement and of the demand displacement spectrum. The rocking analy- sis, instead, correctly reproduced the stability of the gable and the collapse of the upper façade. Naturally, also in the rocking analysis many uncertainties were found, such as the amplification of the action when the block is not at the building base. This amplification factor was demonstrated to be crucial for stating the survival or the collapse of the block. However, the latter approach is believed to be by the authors more reliable and plausible for the seismic response of rigid blocks.

\section{ACKNOWLEDGEMENTS}

The authors wish to thank Ing. Luciano Bellesia for his helpful cooperation. The activity is cosponsored by Consortium RELUIS - Masonry 2014.

\section{PUBLICATION BIBLIOGRAPHY}

NTC2008 (1/14/2008): Approvazione delle Nuove Norme Tecniche per le Costruzioni. In : Gazzetta Ufficiale della Repubblica Italiana n. 29, February, 28th 2008, Supplemento Ordinario n. 30.

Brencich, A.; Lagomarsino, S. (1997): Un modello a macroelementi per l'analisi ciclica di pareti murarie. In Proceedings of the 8th National Conference ANIDIS, Taormina.

Circolare esplicativa del 02.02.2009 contenente "Istruzioni per l'applicazione delle nuove norme tecniche per le costruzioni di cui al D.M. 14.01.2008" (In italian).

EERI Special Earthquake Report (2007): Learning from earthquakes. The Pisco, Peru, earthquake of August 15, 2007.

Giresini, L.; Fragiacomo, M.; Lourenço, P. B. (2015): Comparison between rocking analysis and kinematic analysis for the dynamic out-of-plane behavior of masonry walls. In Earthquake Engineering and Structural Dynamics. DOI: 10.1002/eqe.2592.

Giresini, L.; Sassu, M. (2015): Evaluation of horizontal restraints effectiveness on rocking blocks in static and dynamic approaches. Unpublished work.

Housner, G. W. (1963): The behavior of inverted pendulum structures during earthquakes. In Bulletin of the Seismological Society of America 53 (2), pp. 403-417.

Luzi, L.; Hailemikael, D.; Bindi D.; Pacor, F.; Mele, F.; Sabetta F. (2008): A Web Portal for the Dissemination of Italian Strong-motion Data, Seismological Research Letters. In Seismological Research Letters 75 (9), pp. 716722. DOI: $10.1785 / \mathrm{gssrl} .79 .5 .716$.

Makris, N.; Kostantinidis, D. (2003): The rocking spectrum and the limitations of practical design methodolo- 
gies. In Earthquake Engineering \& Structural Dynamics 32, pp. 265-289. DOI: 10.1002/eqe.223.

Pacor, F.; Paolucci, R.; Luzi, L.; Sabetta F.; Spinelli, A.; Gorini, A. et al. (2011): Overview of the Italian strong motion database ITACA 1.0. In Bulletin of Earthquake Engineering 9 (6), pp. 1723-1739. DOI: 10.1007/s10518011-9327-6.

Sorrentino, Luigi; Kunnath, Sashi; Monti, Giorgio; Scalora, Giuseppe (2008): Seismically induced one-sided rocking response of unreinforced masonry façades. In Engineering Structures 30 (8), pp. 2140-2153. DOI: 10.1016/j.engstruct.2007.02.021.

The Getty Conservation Institute (Ed.) (2012): Seismic Retrofitting Project: Assessment of Prototype Buildings: volume 1. Cancino, C.; Lardinois, S.; D’Ayala, D.; Fonseca Ferreira, C.; Torrealva Dàvila, D.; Vicente, E.; Santamato. With assistance of L. Los Angeles. 